\title{
A DC-DC Converter using the Renewable Energies for Battery Charger
}

\author{
Jin-Hong Kim ${ }^{1}$, Jun-Hyuk Choi ${ }^{1}$ \\ ${ }^{1}$ Korea Electronics Technology Institute \\ 203-101 Bucheon-TP B/D 192, \\ Yakdae-dong, Wonmi-gu,Bucheon-si, Gyeonggi-do (South Korea) \\ Phone number: +82 32-621 2859, e-mail: kimjinhong@keti.re.kr, cjh@keti.re.kr
}

\begin{abstract}
With a development of Hybrid Electric Vehicle (HEV), a photovoltaic(PV) generation system is used for charging batteries in many cases. A dc/dc converter using PV power for a battery charger requires a high efficiency. In this paper, A zero voltage switching (ZVS) boost converter using the renewable energies for HEV charger is proposed. Through the theoretical analysis and experimental result, operation modes and characteristics of the proposed topology are verified.
\end{abstract}

\section{Key words}

Battery charger, soft switching, boost converter.

\section{Introduction}

An energy crisis has become a global issue due to its scarcity and high rocketing price of fossil energy resources. And $\mathrm{CO}_{2}$ emission has stabilized and the temperature has increased. For these reasons, renewable energy and Hybrid Electric Vehicle (HEV) have been brought to public attention, and a considerable number of researches have been conducted on these fields [1]. In general, HEV is composed of the battery pack, the traction motor, the inverter and the engine [2]. The capacity of the batteries is one of the determining factors of HEV mileage [3]. So it is important that the battery is charged enough. Therefore, a $\mathrm{dc} / \mathrm{dc}$ converter is needed for the battery energy storage system. Also, if renewable energy is used for charging the car during the car is parked, the electric charges can be saved.

In this paper, a ZVS boost converter using renewable energies for HEV charger station is proposed. The proposed system contains a Maximum Power Point Tracking (MPPT) algorithm [4] and a Constant CurrentConstant Voltage(CC-CV) control method[5]. By using a resonance circuit, the proposed topology can reduce the switching loss because the switch is turned on and off with zero voltage switching (ZVS). The proposed topology is verified through simulation and experimental results.

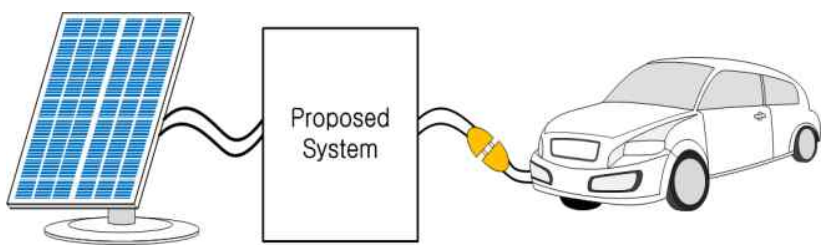

Fig. 1 A schematic of the proposed system

\section{Proposed Soft Switching Converter}

\section{A. Composition of proposed converter}

Fig. 1 shows a schematic of the proposed system. The proposed system transfers a DC power from PV array to batteries of a HEV.

Fig. 2 shows a schematic of the proposed a soft switching boost converter using the PV power for HEV charger station. The proposed converter is based on a conventional boost converter with a soft switching cell that consists of a resonant inductor $L_{r}$, a resonant capacitor $C_{r}$ and a snubber capacitor $C_{s}$.

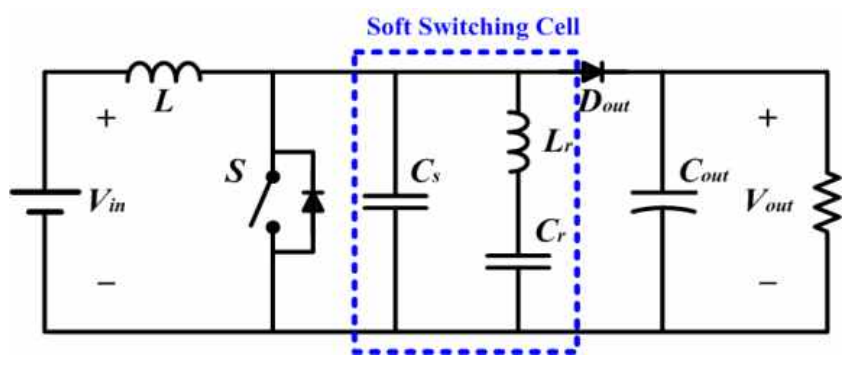

Fig. 2 A schematic of the proposed converter

\section{B. Operation mode}

In this section, an operating mode analysis of the proposed converter is performed according to the different current paths of each elements and the voltage 
of the switch. The proposed topology is divided into 7 modes. Fig. 3 shows the key waveforms of the proposed converter during a single switching period. Fig. 4 shows the operation modes.

MODE $1\left(\boldsymbol{t}_{\boldsymbol{0}} \leq \boldsymbol{t}<\boldsymbol{t}_{1}\right)$ : Mode 1 starts when the switch is turned on. The main inductor current $\left(i_{L}\right)$ flows to switch and resonant circuit. During this mode, the resonant inductor current $\left(i_{L r}\right)$ decreases to zero. When the resonant capacitor $(C r)$ is full charged, Mode 1 is finished.

$i_{L r}(t)=i_{L}\left(t_{0}\right) \cos \omega_{r} t-\frac{v_{C r}\left(t_{0}\right)}{Z_{r}} \sin \omega_{r} t$

$v_{C r}(t)=v_{C r}\left(t_{0}\right) \cdot \cos \omega_{r} t+i_{L}\left(t_{0}\right) \cdot Z_{r} \sin \omega_{r} t$

Where the characteristic impedance $\left(Z_{r}\right)$ and the resonant angular frequency $\left(\omega_{r}\right)$ are defined in Eq. (3)

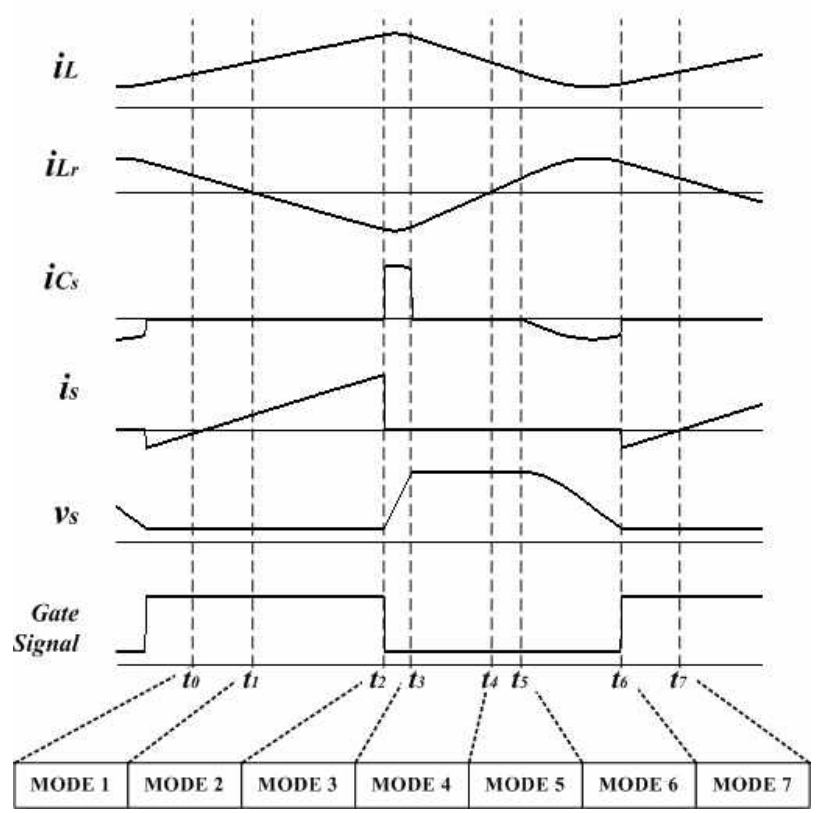

Fig. 3 Key waveforms of the proposed converter
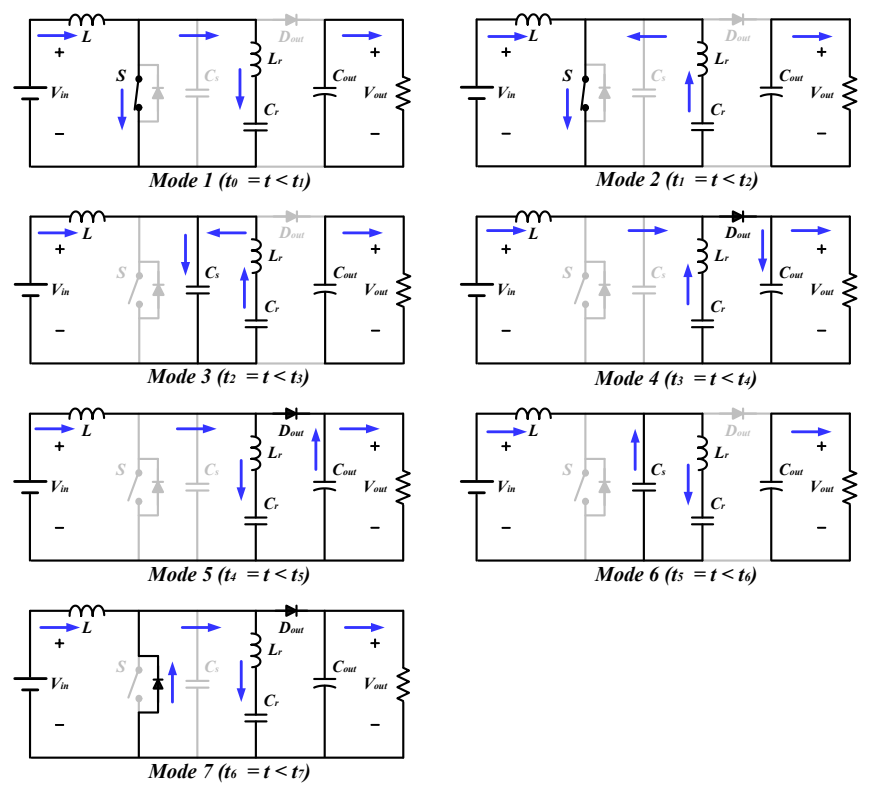

Fig. 4 Operation modes of proposed converter

$\omega_{r}=\frac{1}{Z_{r}}, Z_{r}=\sqrt{L_{r} \cdot C_{r}}$.

MODE $2\left(\boldsymbol{t}_{1} \leq \boldsymbol{t}<\boldsymbol{t}_{2}\right)$ : At time $\mathrm{t}_{1}$, the direction of $i_{L r}$ is changed. $i_{L}$ and $i_{L r}$ are added together and the resulting current flows to the switch.

$i_{L r}(t)=-\frac{v_{C r}\left(t_{1}\right)}{Z_{r}} \sin \omega_{r} t$

$v_{C r}(t)=v_{C r}\left(t_{1}\right) \cdot \cos \omega_{r} t$

MODE $3\left(\boldsymbol{t}_{2} \leq \boldsymbol{t}<\boldsymbol{t}_{3}\right)$ : This mode is started when the switch $\mathrm{S}$ is turned off with ZVS condition, due to the snubber capacitor $(C s) . i_{L}$ and $i_{L r}$ flows to $C_{s}$ together and $C_{s}$ is charged. When $C_{S}$ is full charged, mode 3 ends.

$$
\begin{aligned}
i_{L r}(t)= & \frac{C}{C_{s}} i_{L}\left(t_{2}\right)+\left(i_{L r}\left(t_{2}\right)-\frac{C}{C_{s}} i_{L}\left(t_{2}\right)\right) \cos \omega_{a} t \\
& -\frac{v_{C r}\left(t_{2}\right)}{Z_{a}} \sin \omega_{a} t \\
v_{C r}(t)= & \frac{i_{L}\left(t_{2}\right)}{C_{r}+C_{s}} t+\frac{C}{C_{s}} \cdot v_{C r}\left(t_{2}\right) \cdot\left(1+\frac{C_{s}}{C_{r}} \cos \omega_{a} t\right) \\
& +\frac{C}{C_{r}} Z_{a}\left(i_{L r}\left(t_{2}\right)-\frac{C}{C_{s}} i_{L}\left(t_{2}\right)\right) \sin \omega_{a} t \\
v_{C s}(t)= & \frac{i_{L}\left(t_{2}\right)}{C_{r}+C_{s}} t+\frac{C}{C_{s}} \cdot v_{C r}\left(t_{2}\right) \cdot\left(1-\cos \omega_{a} t\right) \\
& +\frac{C}{C_{s}} Z_{a}\left(\frac{C}{C_{s}} i_{L}\left(t_{2}\right)-i_{L r}\left(t_{2}\right)\right) \sin \omega_{a} t
\end{aligned}
$$

where $\omega_{a}=\frac{1}{\sqrt{L_{r} C}}, Z_{a}=\sqrt{\frac{L_{r}}{C}}, C=\frac{C_{r} C_{s}}{C_{r}+C_{s}}$.

MODE $4\left(t_{3} \leq \boldsymbol{t}<\boldsymbol{t}_{4}\right):$ At time $\mathrm{t}_{3}$, the voltage across $C s$ is equal to output voltage ( Vout) and output diode (Dout) begins to conduct. The saved energy of the main inductor $(L)$ and the resonant circuit are transmitted to the load through Dout. Mode 4 ends when $C_{r}$ is fully discharged and the direction of $i_{L r}$ is changed.

$$
\begin{aligned}
i_{L r}(t)= & i_{L r}\left(t_{3}\right) \cdot \cos \omega_{r} t+\frac{V_{o}-v_{C r}\left(t_{3}\right)}{Z_{r}} \sin \omega_{r} t \\
v_{C r}(t)= & V_{o}-\left(V_{o}-v_{C r}\left(t_{3}\right)\right) \cos \omega_{r} t \\
& +i_{L r}\left(t_{3}\right) \cdot Z_{r} \sin \omega_{r} t
\end{aligned}
$$

MODE $5\left(\boldsymbol{t}_{\boldsymbol{4}} \leq \boldsymbol{t}<\boldsymbol{t}_{5}\right): i_{L}$ flows to the resonant circuit and the load. $i_{L r}$ changes the direction. When $i_{L}$ has become equal to $i_{L r}$, this mode is finished.

$i_{L r}(t)=\frac{V_{o}-v_{C r}\left(t_{4}\right)}{Z_{r}} \sin \omega_{r} t$ 
$v_{C r}(t)=V_{o}-\left(V_{o}-v_{C r}\left(t_{4}\right)\right) \cdot \cos \omega_{r} t$

MODE $6\left(\boldsymbol{t}_{5} \leq \boldsymbol{t}<\boldsymbol{t}_{6}\right)$ : Mode 6 starts with discharging of Cs. When the voltage across $C$ s becomes lower than Vout, Dout turns off and mode 6 ends.

$$
\begin{aligned}
i_{L r}(t)= & \frac{C}{C_{s}} i_{L}\left(t_{5}\right)\left(1+\frac{C_{s}}{C_{r}} \cos \omega_{a} t\right) \\
& +\frac{V_{o}-v_{C r}\left(t_{5}\right)}{Z_{a}} \sin \omega_{a} t \\
v_{C r}(t)= & \frac{I_{L}\left(t_{5}\right)}{C_{r}+C_{s}} t+v_{C r}\left(t_{5}\right) \\
& +\frac{C}{C_{r}}\left(V_{o}-v_{C r}\left(t_{5}\right)\right)\left(1-\cos \omega_{a} t\right) \\
& +\left(\frac{C}{C_{r}}\right)^{2} i_{L}\left(t_{5}\right) Z_{a} \sin \omega_{a} t \\
v_{C s}(t)= & \frac{i_{L}\left(t_{5}\right)}{C_{r}+C_{s}} t+\frac{C}{C_{r}} V_{o}\left(1+\frac{C_{r}}{C_{s}} \cos \omega_{a} t\right) \\
& +\frac{C}{C_{s}} \cdot v_{C r}\left(t_{5}\right) \cdot\left(1-\cos \omega_{a} t\right) \\
& -\frac{C}{C_{r}+C_{s}} i_{L}\left(t_{5}\right) Z_{a} \sin \omega_{a} t
\end{aligned}
$$

$$
\text { when } C=\frac{C_{r} C_{s}}{C_{r}+C_{s}}, Z_{a}=\sqrt{\frac{L_{r}}{C}}, \omega_{a}=\frac{1}{\sqrt{L_{r} C}} \text {. }
$$

MODE $7\left(\boldsymbol{t}_{\boldsymbol{6}} \leq \boldsymbol{t}<\boldsymbol{t}_{7}\right)$ : When $i_{L r}$ flows to switch's parallel diode with full discharging of $C s$, this mode starts. The switch $S$ is turned on with ZVS condition. When switch's parallel diode turns off, mode 7 ends.

$i_{L r}(t)=i_{L r}\left(t_{6}\right) \cos \omega_{r} t-\frac{v_{C r}\left(t_{6}\right)}{Z_{r}} \sin \omega_{r} t$

$v_{C r}(t)=v_{C r}\left(t_{6}\right) \cdot \cos \omega_{r} t+i_{L r}\left(t_{6}\right) \cdot Z_{r} \sin \omega_{r} t$

\section{Simulation}

A computer simulation for operational characteristics of proposed dc/dc converter was executed by using PSIM software. The simulation parameters are shown in Table. I. Fig. 5 shows the gate signal, current waveforms, and voltage waveforms of the proposed converter when the input voltage is $80[\mathrm{~V}]$. The output voltage is controlled to DC 400[V].

Fig. 6 shows current and voltage of switch $S$ and Gate signal. The proposed converter is able to perform a ZVS. So it is expected that efficiency of proposed converter is higher than that of a conventional boost converter.

Fig. 7 shows control blocks of proposed system. The proposed system requires a MPPT control for an input power and a CC-CV control for an output power. If control signals of two control methods are mutually exclusive, a
$\mathrm{CC}-\mathrm{CV}$ control is must be a priority factor.

TABLEI.

SIMULATION PARAMETERS

\begin{tabular}{|c|c|}
\hline Parameter & Value \\
\hline \hline Main inductor $L$ & $500[\mu \mathrm{H}]$ \\
\hline Resonant inductor $L r$ & $100[\mu \mathrm{H}]$ \\
\hline Snubber capacitor $C s$ & $60[\mathrm{nF}]$ \\
\hline Resonant capacitor $C r$ & $2600[\mathrm{nF}]$ \\
\hline Output capacitor Cout & $500[\mu \mathrm{F}]$ \\
\hline Input voltage & $80[\mathrm{~V}]$ \\
\hline Output voltage & $400[\mathrm{~V}]$ \\
\hline Power & $400[\mathrm{~W}]$ \\
\hline
\end{tabular}
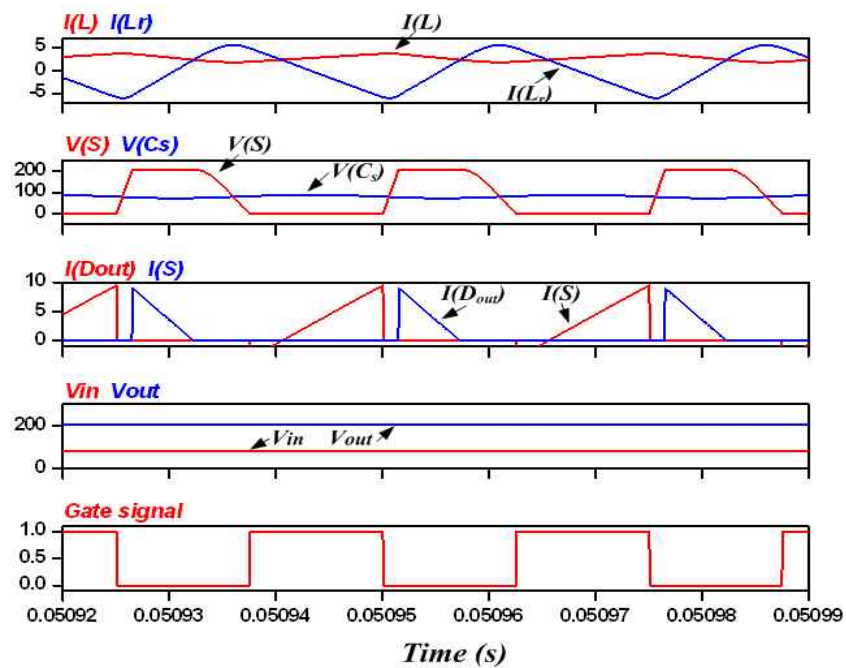

Fig. 5 Current waveforms, voltage waveforms and gate signal of the proposed converter
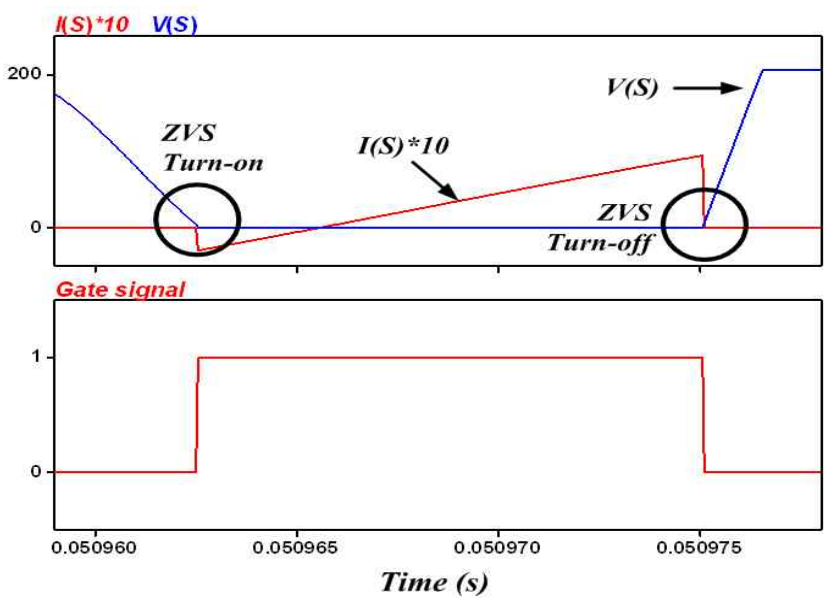

Fig. 6 Current and voltage of switch S 


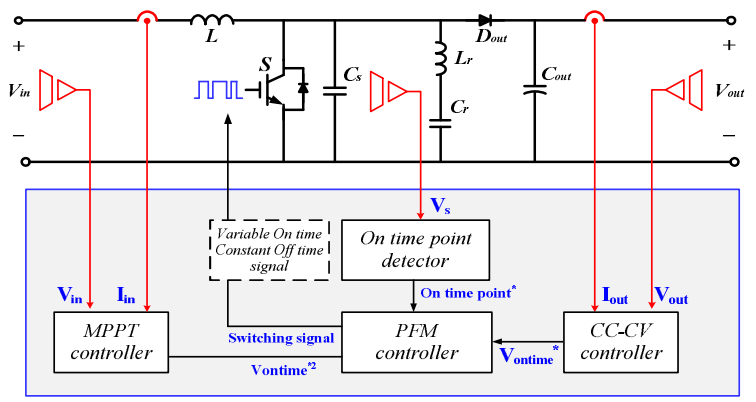

Fig. 7 Control blocks of proposed system

TABLE. II

SPECIFICATIONS OF PROPOSED CONVERTER

\begin{tabular}{|c|c|}
\hline Parameter & Value \\
\hline \hline Main inductor $L$ & $504.2[\mu \mathrm{H}]$ \\
\hline Resonant inductor $L r$ & $101.2[\mu \mathrm{H}]$ \\
\hline Snubber capacitor $C s$ & $66[\mathrm{nF}]$ \\
\hline Resonant capacitor $C r$ & $2660[\mathrm{nF}]$ \\
\hline Output capacitor $C o u t$ & $500[\mu \mathrm{F}]$ \\
\hline
\end{tabular}

\section{Experimental result}

Experiments were conducted on a 400 [W] to verify the analysis and simulation results. The parameters used in the experimental system are given in Table. $\Pi$.

Fig. 8 shows resonant inductor current, switch and resonant capacitor voltage waveforms. The proposed boost converter performs ZVS when switch is turned on and off. Fig. 9 shows resonant inductor current, output and input voltage waveforms.

\section{Conclusion}

In this paper, a soft switching boost converter using the $\mathrm{PV}$ power for HEV charger station is proposed. The proposed topology is verified through simulation and experimental results. The proposed topology performs ZVS when the switch is turned on and off.The proposed topology can deliver renewable energies to batteries with high efficiency. So it is expected that the proposed topology makes renewable energies more useful.

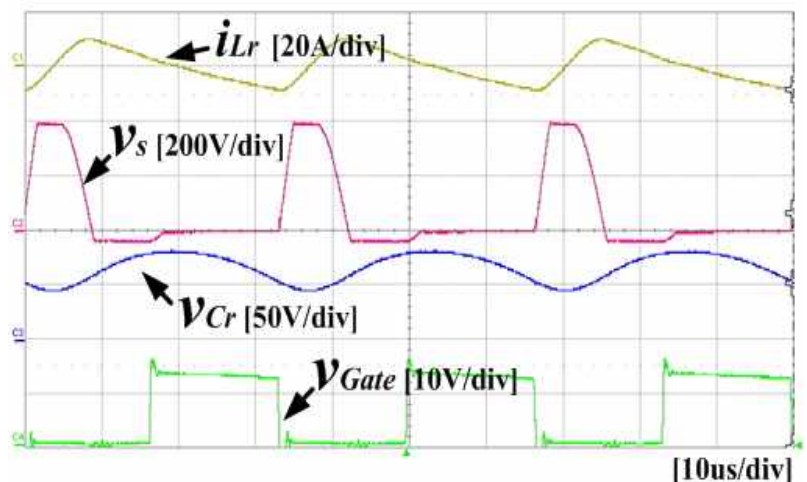

Fig. 8 Resonant Inductor current, switch and resonant capacitor voltage Waveforms

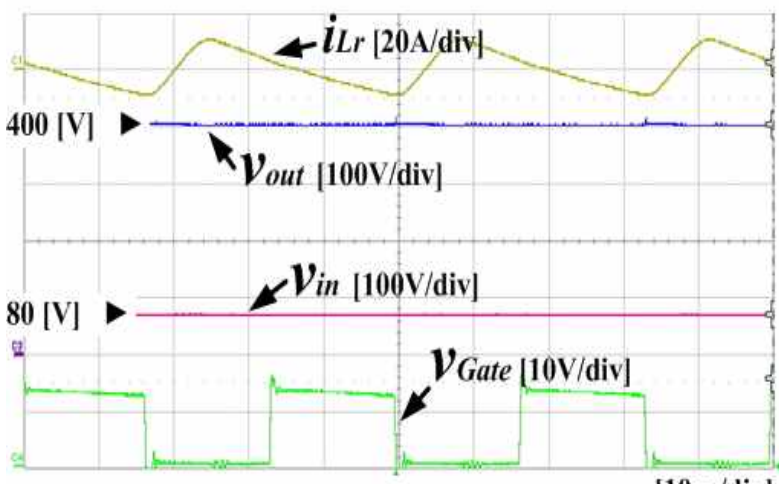

[10us/div]

Fig. 9 Resonant Inductor current, output and input voltage Waveforms

\section{Reference}

[1] Ertan, H.B., Simsir, B., "A pulse frequency modulated drive for a wide speed range application", Power Electronic Drives and Energy Systems for Industrial Growth, 1998. Proceedings. 1998 International Conference on Volume 2, 1-3 Dec. 1998 Page(s):546 - 551

[2] Xu Zhang, Maksimovic, D., "Digital PWM/PFM controller with input voltage feed-forward for synchronous buck converters", Applied Power Electronics Conference and Exposition, 2008. APEC 2008. Twenty-Third Annual IEEE, 24-28 Feb. 2008 Page(s):523 - 528

[3] Doo-Yong Jung, Young-Hyok Ji, Chung-Yuen Won, SuWon Lee, Yong-Chae Jung, "Loss analysis in soft switching boost converter using a single switch", Power Electronics and Motion Control Conference, 2009. IPEMC '09. IEEE 6th International 17-20 May 2009 Page(s):1416 $-1420$

[4] Jain N., Jain P.K., Joos G., "A zero voltage transition boost converter employing a soft switching auxiliary circuit with reduced conduction losses", Power Electronics, IEEE Transactions on Volume 19, Issue 1, pp. 130-139, 2004.

[5] Jovanovic M.M., Yungtack Jang, "A new, soft -switched boost converter with isolated active snubber", Industry Applications, IEEE Transactions on Volume 35, Issue 2, pp. 496-502, 1999.

[6] Lambert J.A., Vieira J.B. Jr., Carlos de Freitas L., dos Reis Barbosa L., Farias V.J., "A boost PWM soft-singleswitched converter with low voltage and current stresses", Power Electronics, IEEE Transactions on, Volume 13, Issue 1, pp. 26-35, 1998.

[7] Xinke Wu, Junming Zhang, Xin Ye, Zhaoming Qian, "Analysis and Design for a New ZVS DC-DC Converter With Active Clamping", Power Electronics, IEEE Transactions on, Volume 21, Issue 6, pp. 1572-1579, 2006. 